\title{
Microscopylmages
}

\section{Microscopy Today Micrograph Awards}

\author{
Charles Lyman, Senior Editor
}

The third Microscopy Today Micrograph Awards competition was successful (even in the year of the pandemic). The premise of these competitions is that scientific micrographs can be interesting in their own right as images with visual impact. Submissions came from over 20 countries. The judges could not see the names or affiliations of the submitters. Of the 25 finalist micrographs (on the July cover and in the Microscopy Today micrograph gallery at https://www.microscopy. org/awards/micrograph_gallery_2021/), 8 were from the USA, and 17 were from other countries.

In this article, we show the three prize winners in each category: Published category, for micrographs published in the previous year; Open category, for unpublished micrographs; and the Video category, for clips of movies taken through a microscope or of animations of reconstructed images. The images to follow are the first, second, and third prize winners in each category, as well as the winner of the People's Choice Award.

Finalists and prize winners were selected by a panel of judges led by Robert Simmons, and the People's Choice Award was selected via public voting at the competition gallery on the MSA website. The judging panel for the 2021 competition was comprised of five judges, all of whom bring their own special expertise. This year, Robert Simmons (Chief Judge), Charles Lyman (Senior Editor), and Bob Price (Editor-in-Chief) were joined by Esther Bullitt and Beth Appleton. Esther is Associate Professor of Physiology and Biophysics at Boston University School of Medicine and current Past President of MSA. As a structural biologist using electron cryomicroscopy to solve structures of assemblies involved in pathogenesis, she looks for both beauty and function in images: does the image tell a story, and is it striking or beautiful? Beth is a nationally recognized artist living on the Gulf Coast of Florida. She finds inspiration in studying the local aquatic life through her own microscope and applies this to her art. In this way, she hopes to strengthen the bridge between art and science. This group of scientists/artists provides the broad knowledge base needed to address the scientific, technical, and aesthetic aspects of our competition.

The original idea for the Microscopy Today Micrograph Awards competition was proposed by Robert and Camille

\section{Published Category}

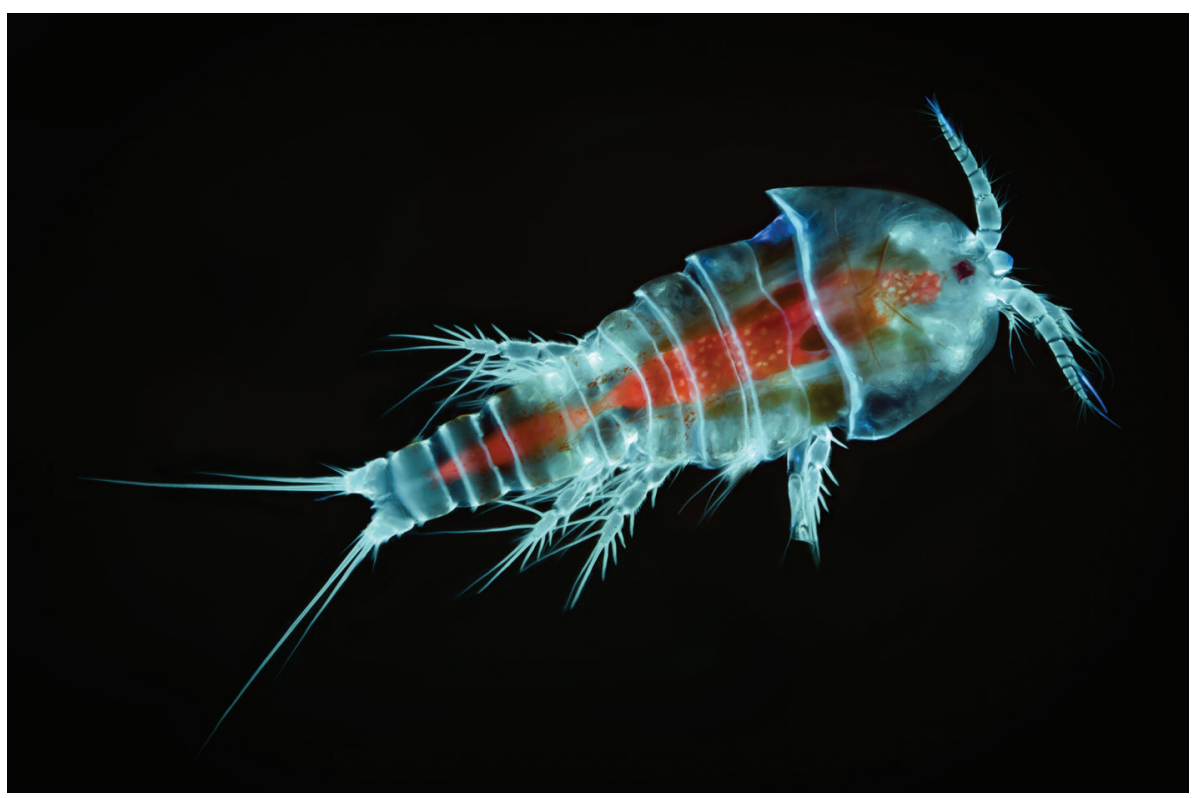

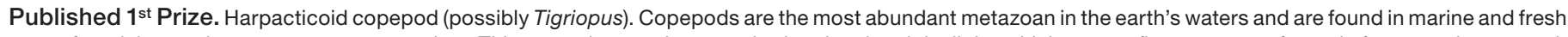

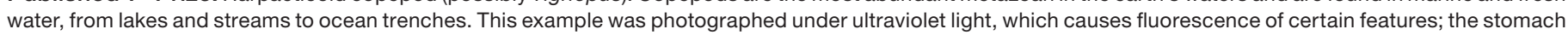

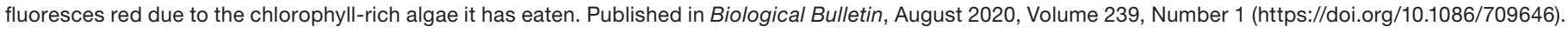
Image by Håkan Kvarnström, Bromma, Sweden. 


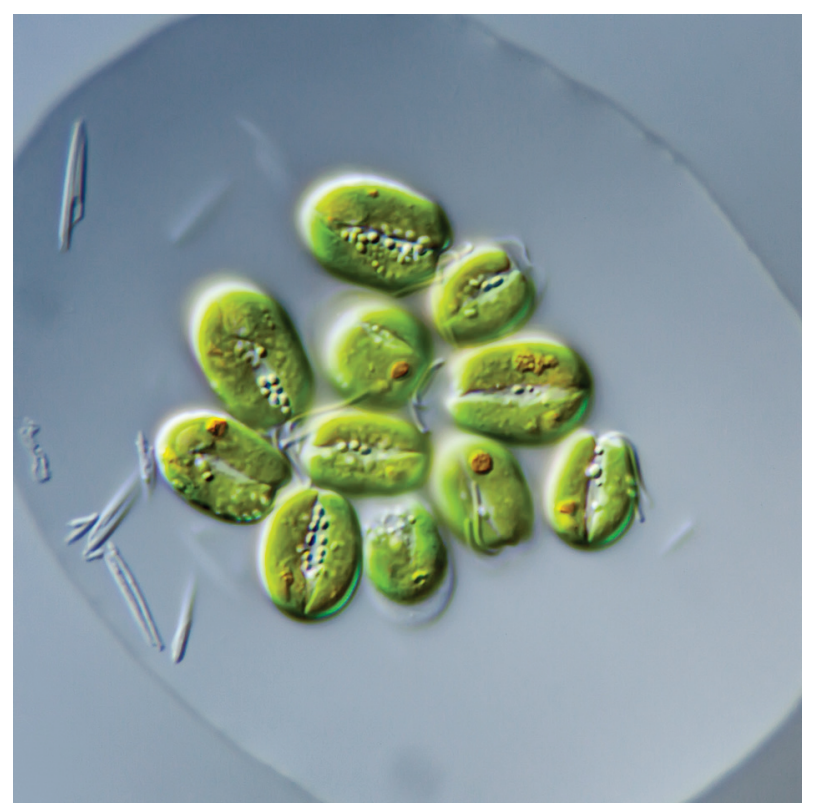

Published $2^{\text {nd }}$ Prize. Tetraselmis suecica cells. Image shows intracellular inclusions of amorphous calcium carbonate, called micropearls. The cultured cells were prepared in vivo together with a thin film of paraffin oil. Differential interference contrast light microscopy. Published in Protist (https://doi.org/10.1016/j. protis.2020.125760). Image by Gerd Günther, independent microscopist, Düsseldorf, Germany.

Simmons. They suggested in 2017 that Microscopy Today sponsor a micrograph contest emphasizing both the scientific and artistic merit of micrographs. This concept was developed during 2018, when a prospectus and a set of specifications for micrograph submission software were produced. Nestor Zaluzec made the submission software capable of dealing with hundreds of images. When submitting a micrograph, it is important to read and follow the instructions. A complete entry is much easier for the judges to evaluate. The judging process is in two steps: after the scientific relevance of an image has been established, the judges evaluate visual impact by asking the following: Can the micrograph stand on its own as a captivating image without requiring knowledge of the subject or the type of microscopy employed? In other words, would the image look good on a living room or museum wall?

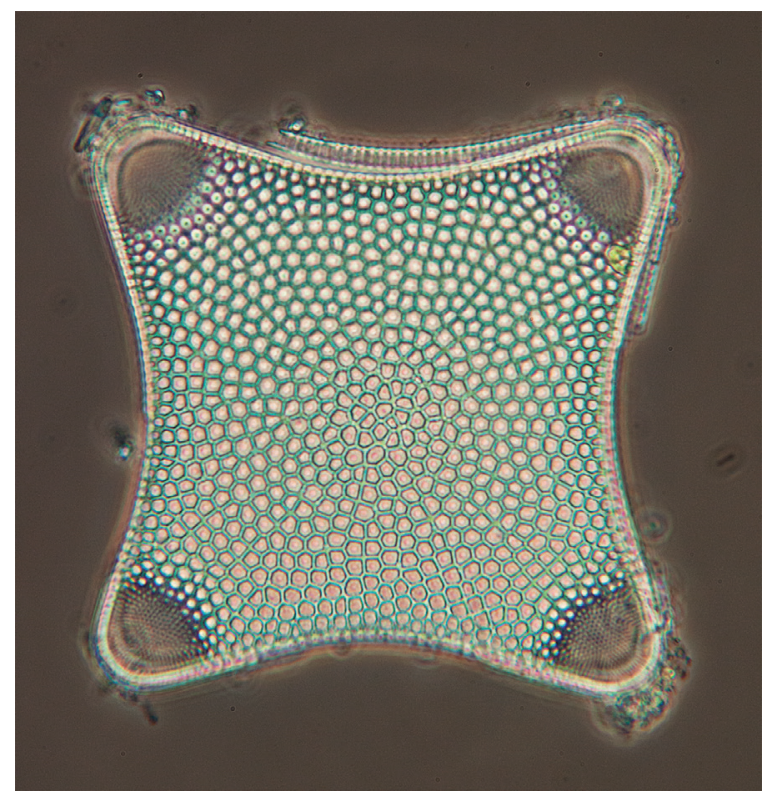

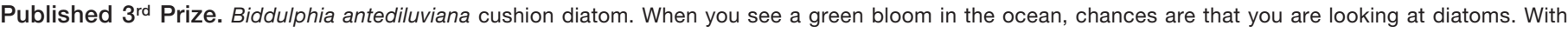

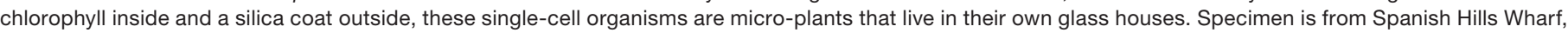

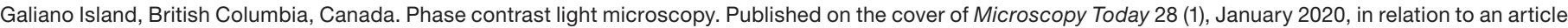
on pages 30-33 (https://doi.org/10.1017/S155192951900124X). Image by Elaine Humphrey, University of Victoria, Victoria, British Columbia, Canada. 


\section{Open Category}

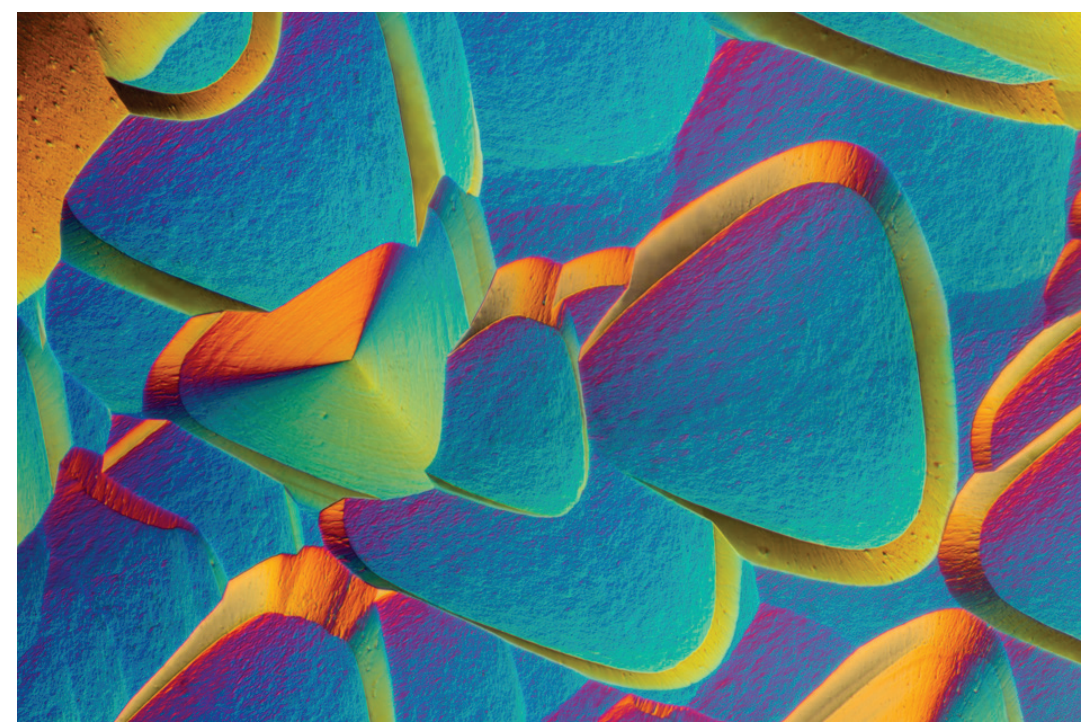

Open $1^{\text {st }}$ Prize. Natural diamond. Surface structure of a natural diamond crystal from Wyoming, USA. Triangular structures known as "trigons" reveal the isometric crystal structure on the octahedral face of the diamond crystal. Differential interference contrast microscopy image formed from 8 separate focus-stacked images. Image by Nathan Renfro, Gemological Institute of America, Escondido, California, USA.

Another goal of our competition is to honor images that may not be eligible or competitive in other micrograph contests. All types of micrographs are welcome in this competition, whether they were acquired with a light microscope, electron microscope, X-ray microscope, scanning probe microscope, or some other microanalytical tool. Also, some worthy micrographs are published in journals or magazines without a thought of entering them in a competition. By honoring published images in a separate category, we hope to encourage microscopists to think about image composition and visual impact in experiment planning and during image acquisition. Understanding mechanisms and processes often requires dynamic imaging acquired by in situ microscopy of all types. Thus, we have established a separate category for video micrographs. This category also includes digital animations of reconstructed three-dimensional datasets, for example from cryo-electron microscopy, which is providing new insights into cellular and molecular structures.

Our competition is also driven by image quality from a technical standpoint. Sharpness of image details is important. Imaging of three-dimensional objects with a large depth of field was once the exclusive domain of the scanning electron

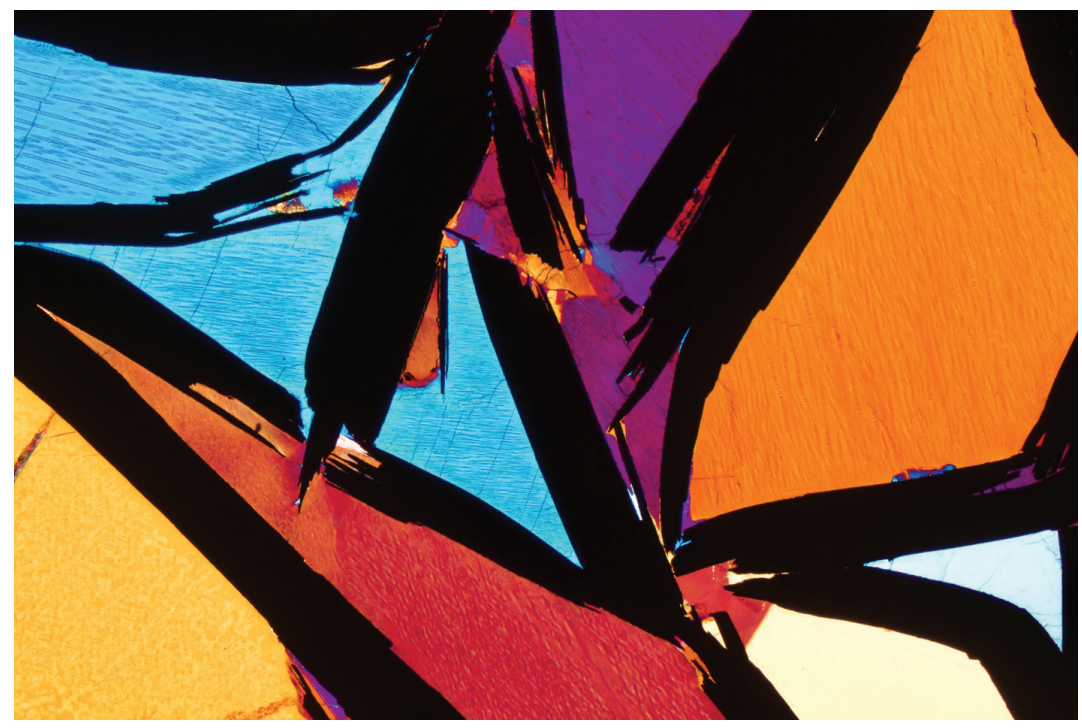

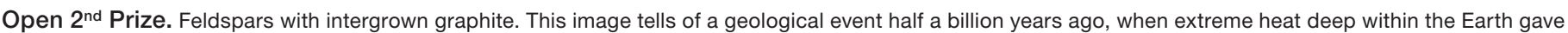

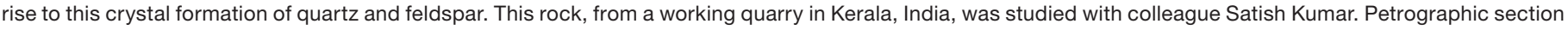
observed by polarized light microscopy. Image by Bernardo Cesare, University of Padova, Padova, Italy. 


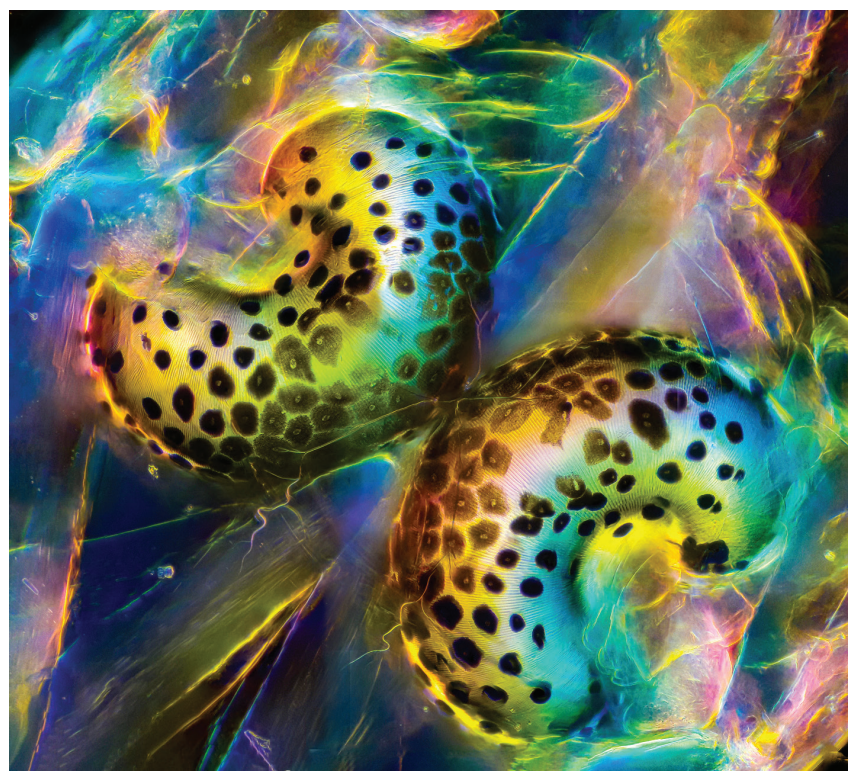

Open $3^{\text {rd }}$ Prize. Midge larva. Tracheal bladders of the midge larva of genus Chaoborus, also known as the glass worm, act as bubbles that regulate the depth of immersion. These larvae are active predators, feeding on small crustaceans (Daphnia, cyclops) and young mosquito larvae. Dark-field and polarized light microscopy. Image by Andrei Savitsky, independent microscopist, Cherkasy, Ukraine.

microscope. But with focus-stacking software, light micrographs now can be in sharp focus over a considerable depth of field. Our judges evaluate submitted micrographs on large high-resolution monitors that can reveal lack of sharpness, as well as other image defects. We request that submitted images have both inherent sharpness and sufficient pixel density to be presented in an $11^{\prime \prime} \times 14$ " format suitable for hanging in an exhibition. Often, image sharpness can be maintained by acquiring the micrograph at a lower magnification than might be required for research purposes. Acquisition at high pixel density is now available to most microscopists since the cost of suitable cameras has decreased dramatically over the last decade. An excellent micrograph with only a modest pixel density is not necessarily eliminated from the competition, but justification may be required to allow the image to be competitive.

So, what makes a winning micrograph? Microscopes reveal interesting features and patterns in objects that are not visible to the naked eye. Some microscopists encounter these

\section{Video Category}

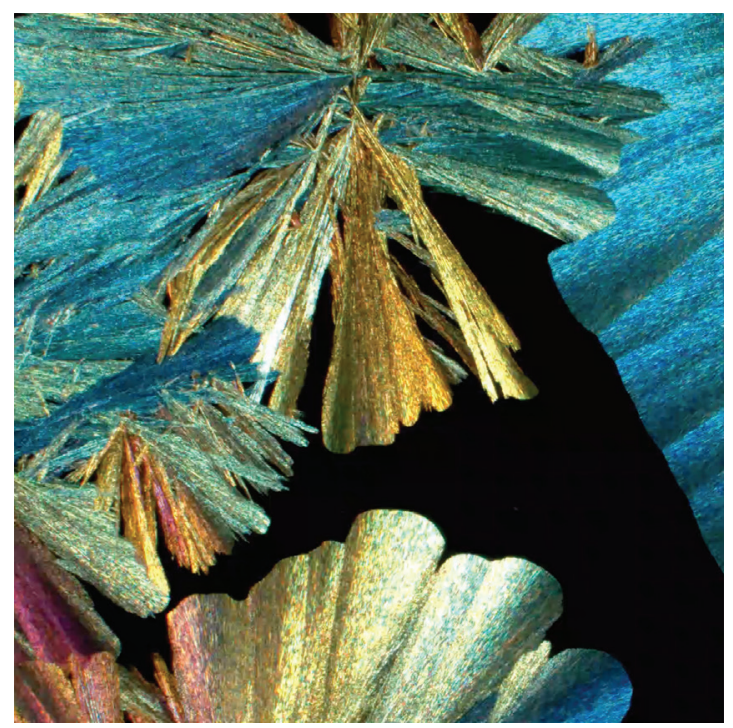

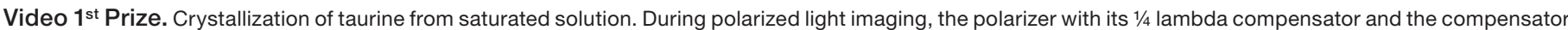

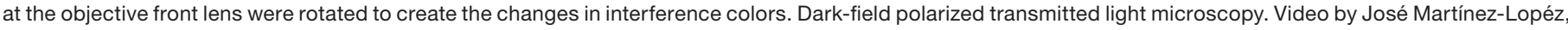
independent microscopist, Juarez, Mexico. 


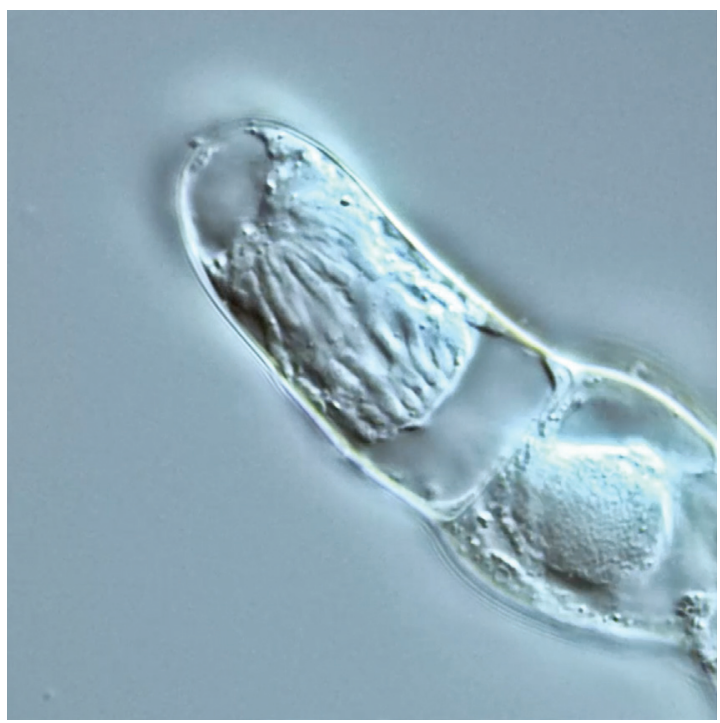

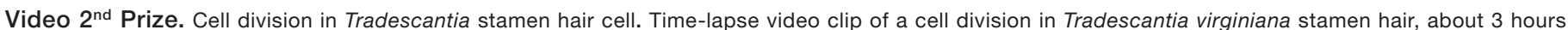

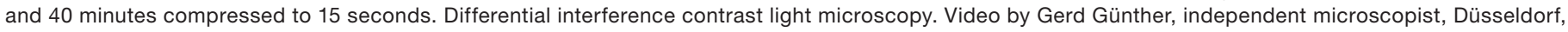
Germany.

images accidentally during the pursuit of other goals, and other microscopists actively seek specific subjects, environmental conditions, or specimen preparation methods that make acquisition of a great image more likely. Whereas the composition of the image is always important, there are other considerations. Micrographs acquired by electron microscopy or scanning probe microscopy are usually monochrome, which does not prevent an image from winning. However, it is now common to "improve" images with post-acquisition processing to add color to features or to change the background color behind the subject. While such manipulation is acceptable, to be successful the microscopist must make good decisions along the way. Choosing to use artificial color in an image is an artistic choice that should be made carefully. While color may enhance a good image, it will not make up for lack of quality in the original. Color choices are important, and discordant colors can reduce the appeal of an image as easily as a lack of sharpness. Post-processing should be undertaken carefully with an eye to improving the appeal or clarity of an image.

The editors and judges of Microscopy Today thank all entrants to this year's competition and welcome their submissions to the next contest. The submission site will re-open on October 1, 2021, and close on February 21, 2022.

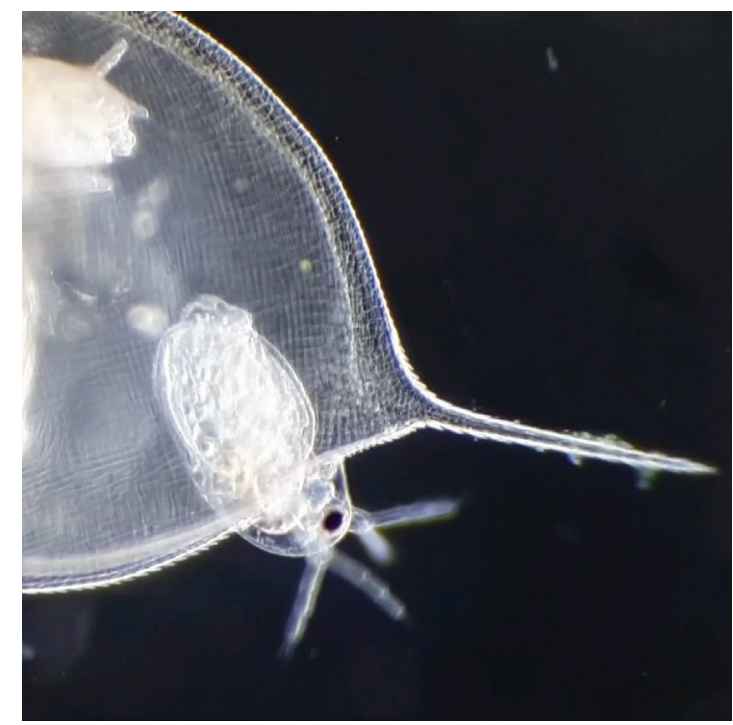

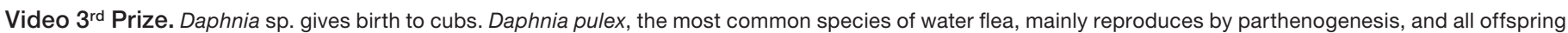

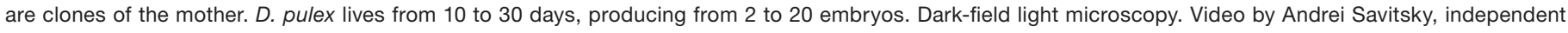
microscopist, Cherkasy, Ukraine. 
People's Choice Award

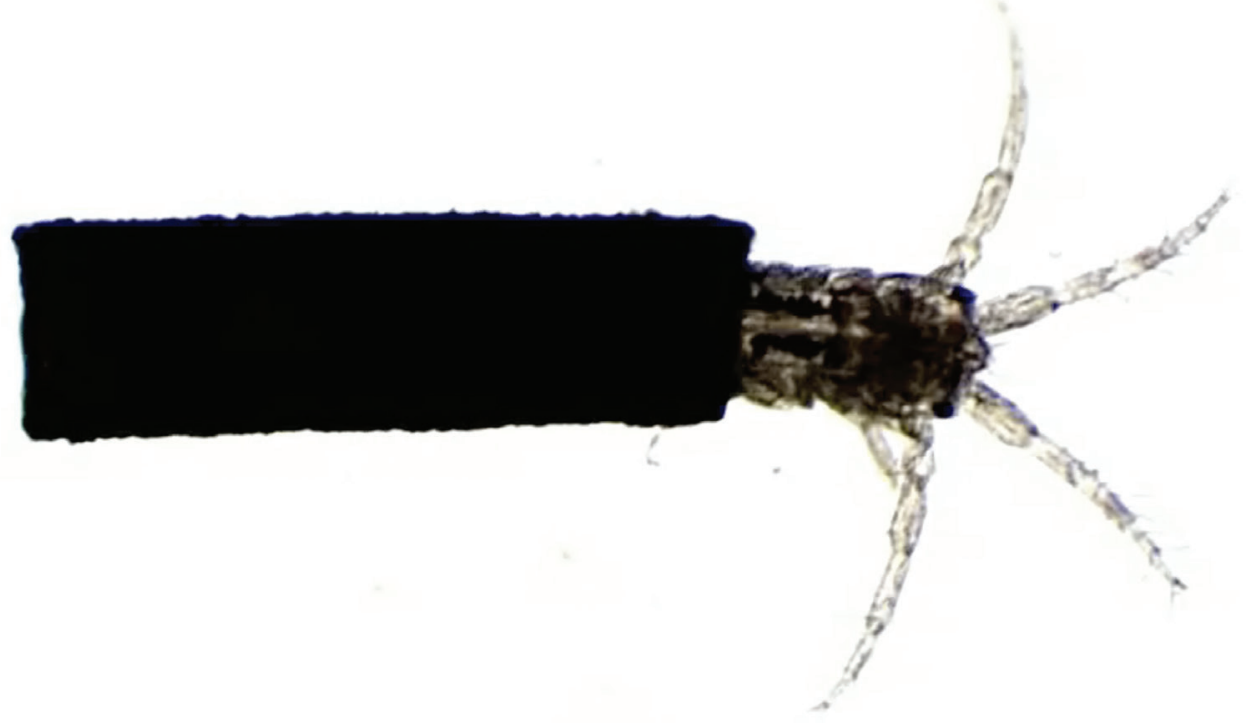

People's Choice Award. Tube-dwelling amphipod (likely Cerapus sp.) flips in and out of its self-made tube, probably looking for food. Bright-field light microscopy. Video by Julia Van Etten, Rutgers University, New Brunswick, New Jersey, USA.

Special Honors
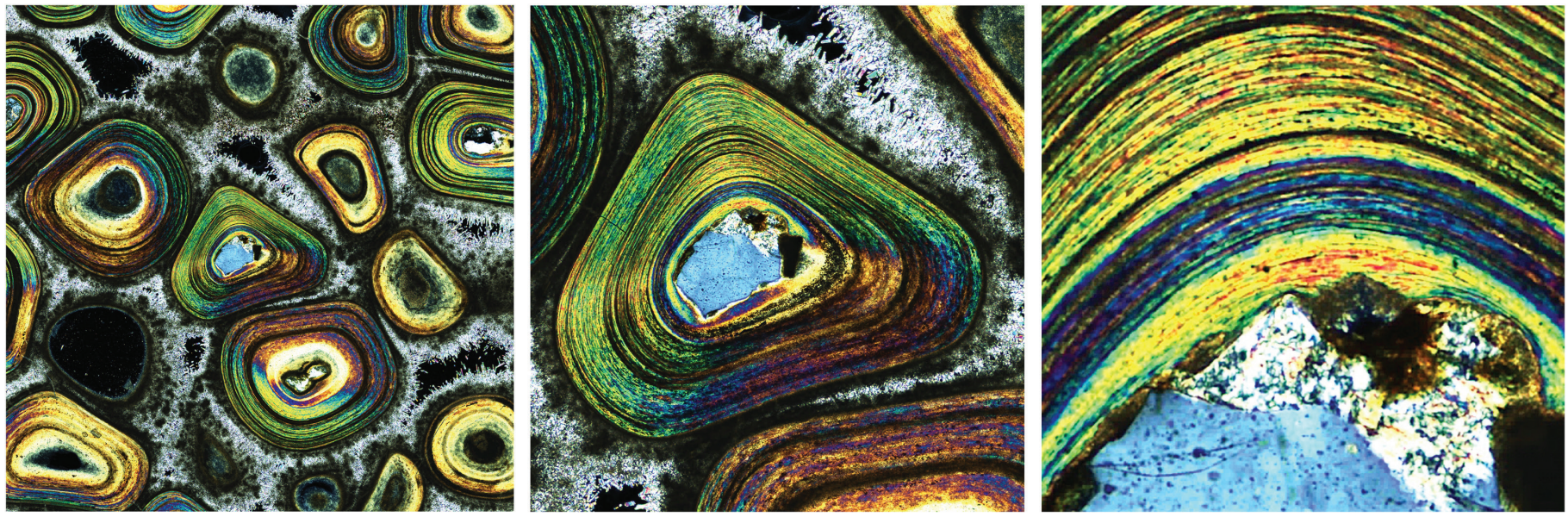

Special Award for petrographic microscopy. Karlsbad Sprudelstein at three magnifications. An unusual sedimentary rock with coated grains (ooids) of aragonite found in the Czech Republic. Thin layers of aragonite form around various internal structures, and needles of aragonite cement keep the grains together like a natural glue. Light micrograph of a petrographic thin section; image produced by stitching together over 100 individual photomicrographs. Sample provided by Axel Munnecke. Image by Bernardo Cesare, University of Padova, Padova, Italy.

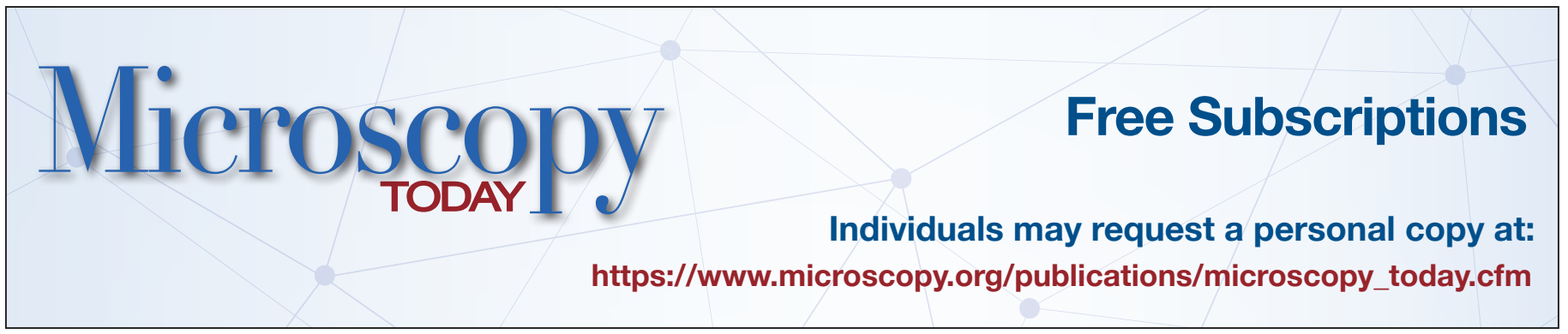

